\title{
Imagen y palabra. Trabajar la Semántica en Educación Primaria
}

CONCEPCIÓN TORRES BEGINES

Dpto. Didáctica de la Lengua y la Literatura y Filologías Integradas. CC de la Educación

ORCID: https://orcid.org/0000-0002-9868-3924

D.O.I.: http://dx.doi.org/10.12795/JDU.2018.i01.54

Pp.: 957-978

\section{Resumen:}

Presentamos un ciclo de mejora llevado a cabo en la asignatura de Lengua Española y su Didáctica del Grado de Educación Primaria de la Universidad de Sevilla. En concreto, se ha trabajado sobre el tema de Semántica. Se ha tenido en cuenta la formación en procedimientos y actitudes con el diseño de un taller de poesía visual destinado a un colectivo en riesgo de exclusión. Para evaluar todo el ciclo, se presentan unas escaleras de aprendizaje que muestran la evolución de los conocimientos de los alumnos en base a unas preguntas clave a las que se ha ido dando respuesta a lo largo de las diez sesiones.

Palabras clave: Aprendizaje Servicio, Educación Primaria, docencia universitaria, experimentación docente universitaria, Lengua Española

Esta obra se distribuye con la licencia Creative 


\section{La asignatura de Lengua Española: problemas detectados y cambios propuestos}

Este ciclo de mejora se ha aplicado en la asignatura de Lengua Española del Grado de Primaria de la Universidad de Sevilla, la cual tuvimos la suerte de impartir brevemente durante el curso 2017/2018. La hemos elegido por detectar durante ese tiempo su tendencia, como muchas otras materias del área, a seguir un planteamiento eminentemente filológico, dándole importancia a los contenidos conceptuales por encima de los demás. Esto ha provocado que los alumnos la perciban como una asignatura puramente teórica, de aprendizaje memorístico. Para evitarlo y buscando una mayor motivación, lo que se traducirá en un aprendizaje más significativo, se proponen cuatro cambios esenciales:

1) Elección de contenidos teniendo en cuenta las necesidades del alumnado, esto es, los necesarios para ejercer su labor como maestros de Primaria, frente a otros que, aunque esenciales desde un punto de vista filológico, no van a ser tan útiles.

2) Transformación de la asignatura en eminentemente práctica, centrada en la producción de actividades destinadas a Educación Primaria en las que se trabajen los contenidos aprendidos. Se busca así dotar a los alumnos de un repositorio que tenga una utilidad en el futuro para su labor.

3) Aplicación de la metodología del Aprendizaje Servicio Solidario, dándoles a los alumnos la oportunidad de participar en un proyecto enmarcado en el Programa de Proyectos de Cooperación al Desarrollo de la Universidad de Sevilla. En esta última actividad, totalmente voluntaria, se invitará a los alumnos a diseñar un taller de poesía visual que podrán aplicar en el marco de las actividades realizadas por Fundación Alalá en el

Jornadas de Formación e Innovación Docente del Profesorado I № 1 (2018)
Esta obra se distribuye con la licencia Creative Commons Reconocimiento-NoComercialSinObraDerivada 4.0 Internacional (CC BY-NC-ND 4.0.) 
Polígono Sur. Se busca así darle al alumnado la oportunidad de poner en práctica, de manera real, los conocimientos adquiridos, ayudando además a la concienciación sobre los Objetivos para el Desarrollo Sostenible (ODS), en este caso, en materia de Educación para el Desarrollo.

4) La asignatura de Lengua Española en el Grado de Educación Primaria está estructurada de manera que se van ampliando las unidades estudiadas, comenzando con las mínimas (monemas y fonemas) hasta la mayor (el texto). Sin embargo, el curso pasado se detectó que algunos temas que tenían gran importancia para la formación de los alumnos, como la Semántica, quedaban relegados, dando mayor importancia a otros como la sintaxis, aspecto que, aunque importante a nivel lingüístico, no es esencial para el desarrollo de su labor. En base a esto, proponemos el cambio en el orden de los contenidos. Este cambio se basa en el principio de que si entienden las palabras y aprecian la importancia que el lenguaje tiene en nuestra vida diaria, su adquisición de los demás contenidos será mucho más fluida y motivadora, ya que encontrarán el sentido y la utilidad que tienen todos estos conceptos. Presentamos a continuación la estructura de la asignatura según la guía docente frente a la que proponemos en este ciclo de mejora:

Jornadas de Formación e Innovación Docente del Profesorado I № 1 (2018) Esta obra se distribuye con la licencia Creative 


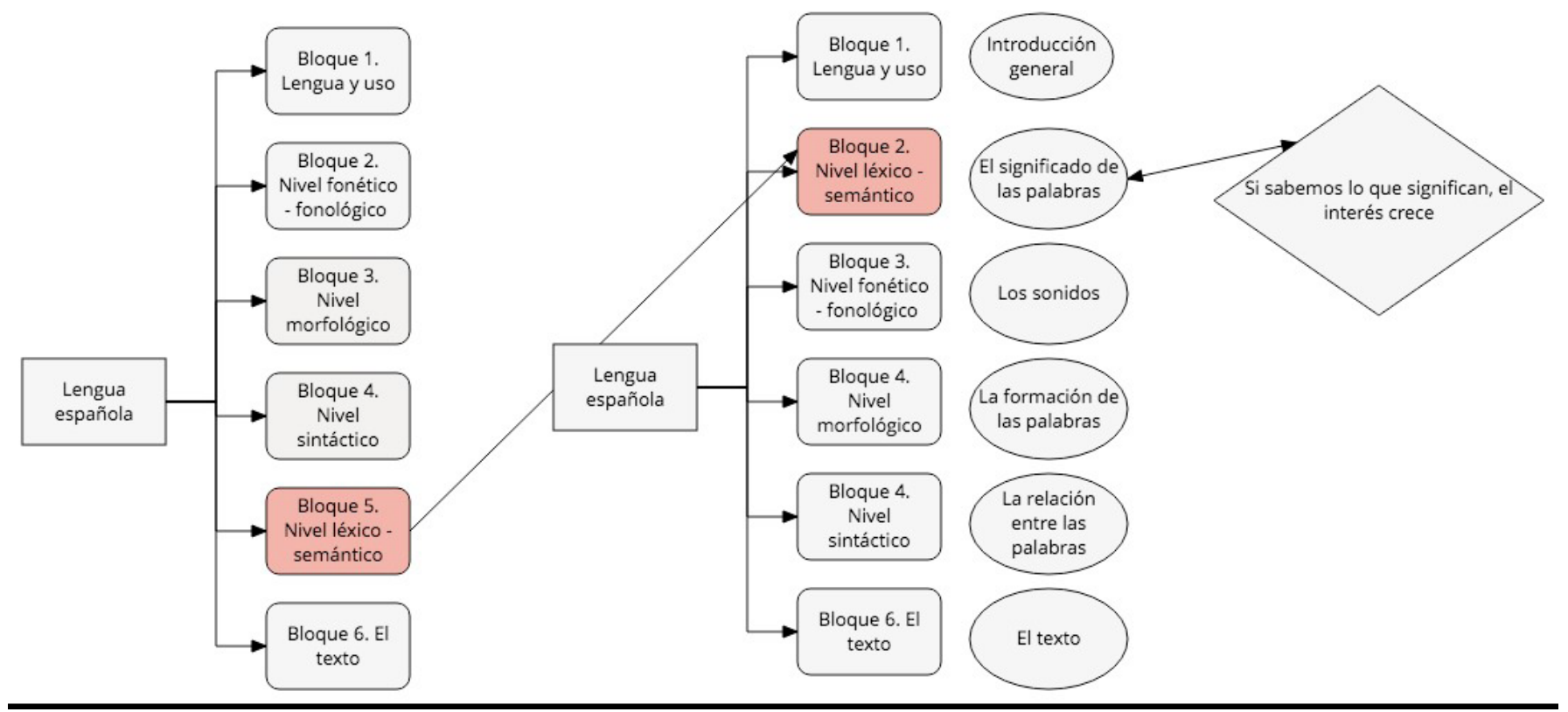

Figura 1. Mapa de organización de la asignatura. Izquierda: planificación oficial de la asignatura. Derecha: planificación propuesta

A la derecha hemos situado además el problema nuclear que se va a tratar en cada uno de los bloques, para que se pueda apreciar esa gradación que señalábamos antes.

Jornadas de Formación e Innovación Docente del Profesorado | № 1 (2018)

(C) (i) Esta obra se distribuye con la licencia Creative

(c) (i) $\Theta$ Commons Reconocimiento-NoComercial-

SinObraDerivada 4.0 Internacional (CC BY-NC-ND 4.0.) 


\section{Diseño previo del ciclo de mejora}

Presentamos el mapa de contenidos pertenecientes al bloque 2: Nivel léxico-semántico, el cual recoge ya un primer filtro de importancia en la formación del alumnado, aunque se adaptará la profundidad con la que se tratarán los temas a su conocimiento previo, evitando así la repetición y centrando la atención en la puesta en práctica y el diseño de materiales.

Para facilitar la localización de los contenidos y la lectura del mapa, hemos establecido cuatro categorías: 1) contenidos que aparecen en el programa de la asignatura y que constituyen lo que podríamos llamar el continente, los cuales facilitarán la relación con el proyecto docente; 2) contenidos teóricos esenciales (SABER) desgranados; 3) contenidos procedimentales (SABER HACER), que responderían a la parte práctica de la asignatura y que serán reflejo de la adquisición de los contenidos teóricos, ya que la asimilación de estos será necesaria para la realización de las prácticas propuestas; 4) en la sección SABER SER, hemos situado los contenidos actitudinales.

Jornadas de Formación e Innovación Docente del Profesorado I № 1 (2018)

(2) Esta obra se distribuye con la licencia Creative Commons Reconocimiento-NoComercialSinObraDerivada 4.0 Internacional (CC BY-NC-ND 4.0.) 


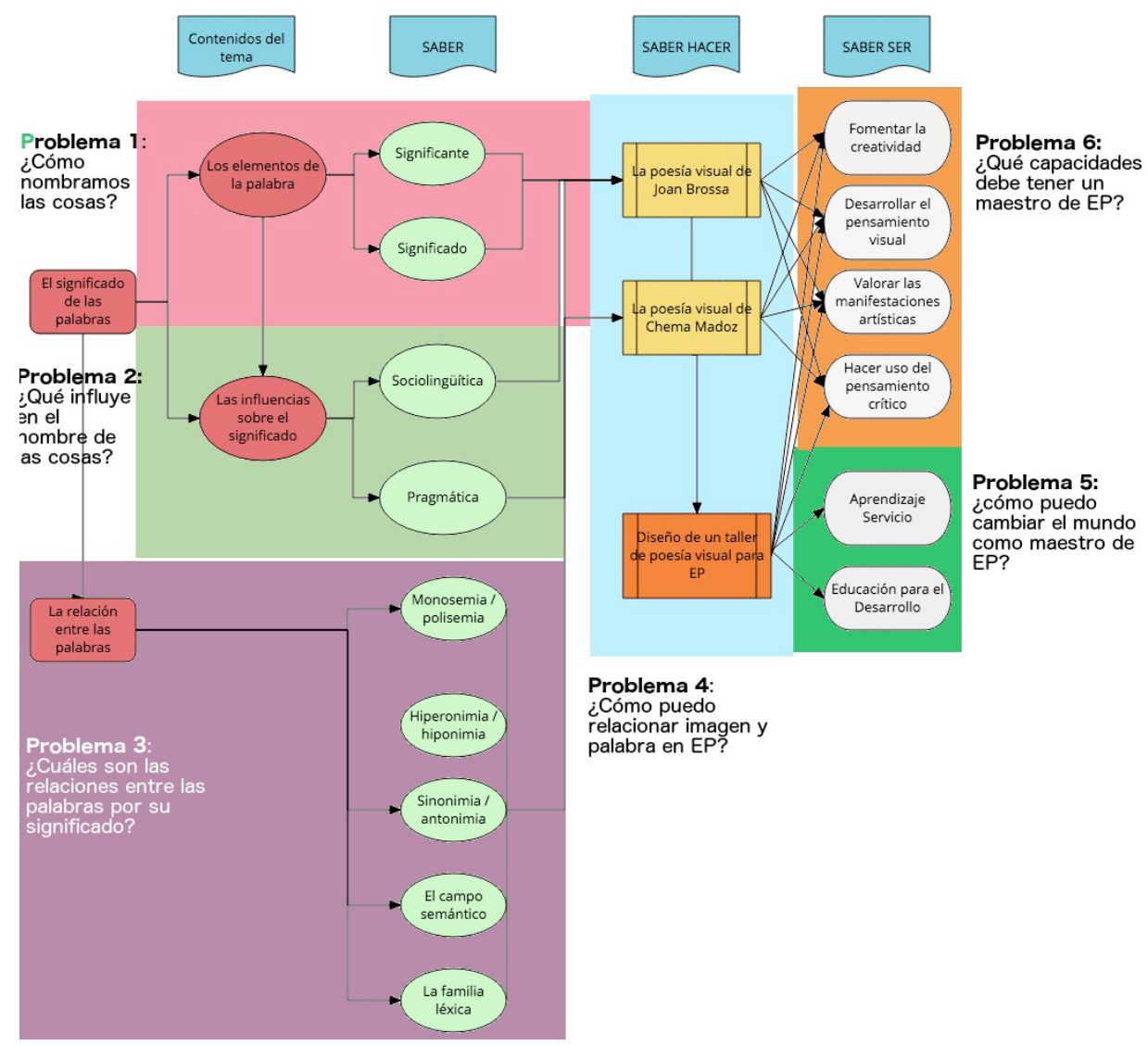

Figura 2. Mapa de contenidos

A partir de este mapa hemos planteado una serie de problemas clave que serán a los que la propuesta va a dar respuesta y que quedan situados en los márgenes, englobando los aspectos con los que se relacionan.

Además, presentamos un mapa de relación de los problemas clave entre sí para terminar de clarificar el peso que cada problema tiene en la propuesta. En el centro hemos situado la relación entre palabra e imagen, puesta en práctica de los contenidos teóricos adquiridos (presentados como problemas a la izquierda) y dando como consecuencia la adquisición de las competencias necesarias.

Jornadas de Formación e Innovación Docente del Profesorado | № 1 (2018)

(c) Esta obra se distribuye con la licencia Creative Commons Reconocimiento-NoComercialSinObraDerivada 4.0 Internacional (CC BY-NC-ND 4.0.) 


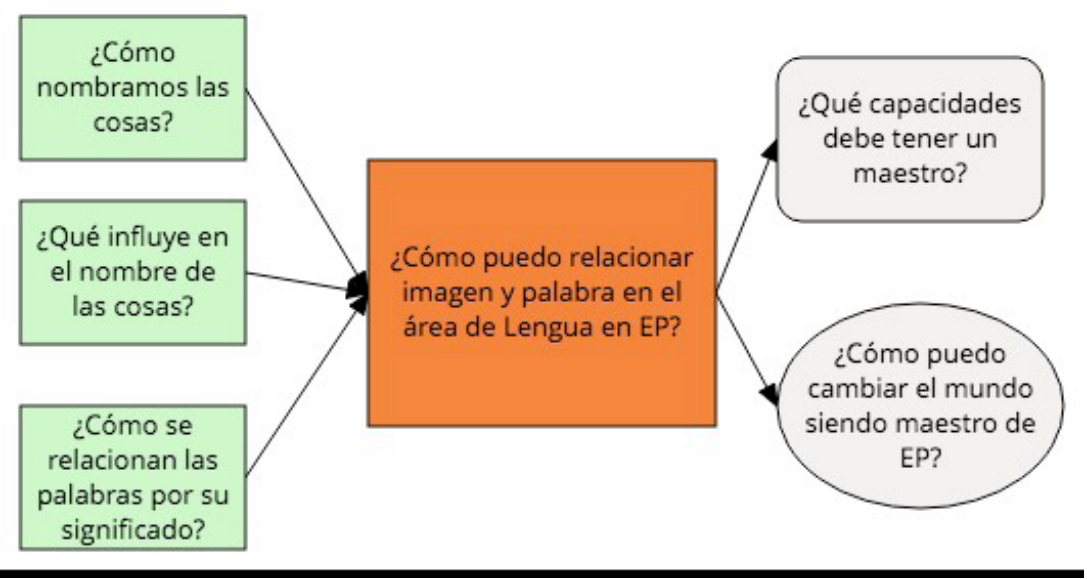

Figura 3. Relación de preguntas clave

\section{Modelo metodológico}

Para establecer nuestro modelo metodológico hemos partido del anterior ciclo de mejora, llevado a cabo en el curso 2017/2018 en la asignatura de Literatura Española en la Escuela Universitaria de Osuna y dividido entre sesiones teóricas y sesiones prácticas.

La primera mejora que proponemos es una unificación del modelo metodológico, no diferenciando entre sesión teórica y sesión práctica. Así, hemos optado por eliminar la alternancia excesiva entre explicación de dinámicas, puesta en común y trabajo autónomo, ya que rompía el ritmo de la clase. Además, hemos mantenido la alternancia entre teoría y práctica con el trabajo autónomo por parte del alumnado, ya que esto les dio independencia para trabajar al ritmo que necesitaran.

Jornadas de Formación e Innovación Docente del Profesorado | № 1 (2018)

Esta obra se distribuye con la licencia Creative Commons Reconocimiento-NoComercialSinObraDerivada 4.0 Internacional (CC BY-NC-ND 4.0.) 

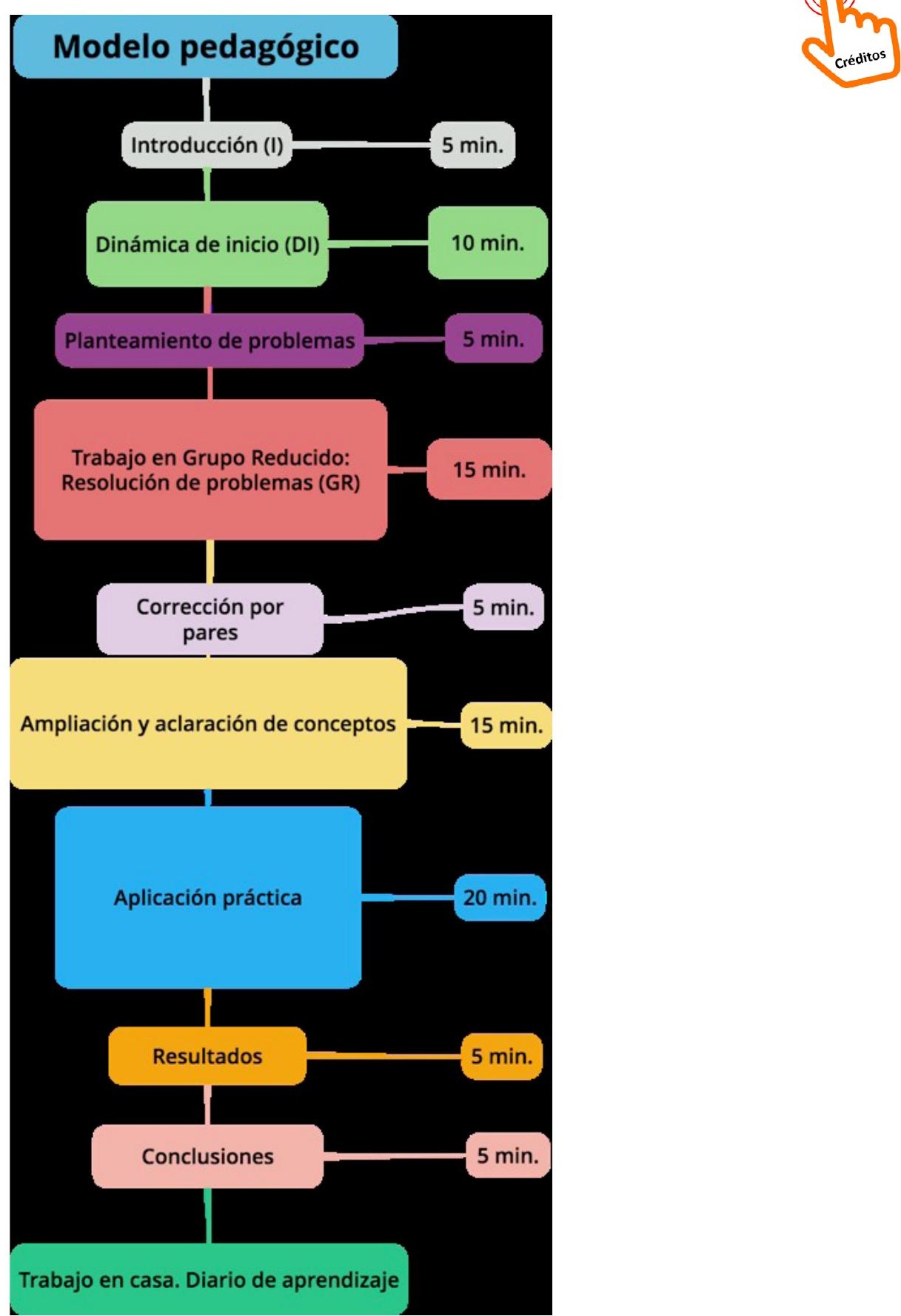

Figura 4. Modelo metodológico 2018/2019

Jornadas de Formación e Innovación Docente del Profesorado | № 1 (2018) (c) (7) Esta obra se distribuye con la licencia Creative Commons Reconocimiento-NoComercialSinObraDerivada 4.0 Internacional (CC BY-NC-ND 4.0.) 


\section{Secuencia de actividades}

Hay que destacar que la propuesta de mejora que presentamos va antecedida por un bloque en el que ya habremos comenzado a hacer uso de las imágenes a través del diseño de memes, por lo que en este partiríamos de una experimentación previa, lo que nos permitirá incluir las mejoras necesarias para el mejor aprovechamiento de la imagen como recurso didáctico.

Se presenta a continuación la planificación de las sesiones. Hemos desarrollado solo el contenido a tratar en los cuatro momentos que varían: Dinámica de Inicio (DI), Planteamiento del Problema (PP), Ampliación y Aclaración de conceptos (A y A) y Aplicación Práctica (AP) para evitar repeticiones innecesarias, ya que las demás partes de la sesión funcionan igual.

Tabla 1

Secuencia de actividades del ciclo de mejora

\begin{tabular}{|c|c|c|c|c|c|c|}
\hline & S1 & S2 & S3 & S4 & S5 & S6 \\
\hline & $01 / 10$ & $04 / 10$ & $08 / 10$ & $09 / 10$ & $11 / 10$ & $16 / 10$ \\
\hline DI & $\begin{array}{l}\text { Ikonikus } \\
\text { Preguntas iniciales } \\
\text { escalera de } \\
\text { aprendizaje }\end{array}$ & Dictado visual & $\begin{array}{l}\text { Pensamiento visual: } \\
\text { música y poesía }\end{array}$ & $\begin{array}{l}\text { Garabatos con } \\
\text { creatividad }\end{array}$ & $\begin{array}{ll}\text { El } & \text { objeto } \\
\text { hablador } & \end{array}$ & $\begin{array}{ll}\text { ¿Cómo } & \text { me } \\
\text { siento? } & \\
\text { Evaluación } & \end{array}$ \\
\hline PP & $\begin{array}{lr}\text { P1: } & \text { ¿Cómo } \\
\text { nombramos } & \text { las } \\
\text { cosas? } & \end{array}$ & $\begin{array}{l}\text { P2: ¿Qué influye en } \\
\text { el nombre de las } \\
\text { cosas? }\end{array}$ & $\begin{array}{l}\text { P3 y P4. ¿Cuál es la } \\
\text { relación que hay entre } \\
\text { imagen y palabra en } \\
\text { estos poemas? Se } \\
\text { muestran poemas } \\
\text { visuales de Joan } \\
\text { Brossa }\end{array}$ & $\begin{array}{l}\text { P4: ¿Qué relación } \\
\text { hay entre poesía y } \\
\text { fotografia? }\end{array}$ & $\begin{array}{l}\text { P3a: ¿Qué } \\
\text { significa banco? } \\
\text { ¿Y banco? } \\
\text { P3b: ¿Cuál es la } \\
\text { relación entre } \\
\text { rojo, colorado, } \\
\text { bermejo y } \\
\text { carmesi? }\end{array}$ & 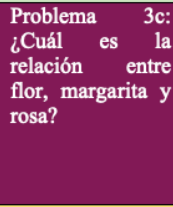 \\
\hline $\begin{array}{l}\text { A } \\
\mathrm{y} \\
\mathrm{A}\end{array}$ & $\begin{array}{l}\text { Los elementos de la } \\
\text { palabra: } \\
\text { significante } \\
\text { significado }\end{array}$ & $\begin{array}{l}\text { Las influencias } \\
\text { sobre el significado. } \\
\text { Sociolingüística y } \\
\text { Pragmática }\end{array}$ & $\begin{array}{l}\text { La poesía visual de } \\
\text { Joan Brossa }\end{array}$ & $\begin{array}{l}\text { La poesía visual de } \\
\text { Chema Madoz. } \\
\text { ¿Qué es la poesía } \\
\text { visual? }\end{array}$ & $\begin{array}{l}\text { Monosemia } \\
\text { polisemia } \\
\text { Sinonimia } \\
\text { antonimia }\end{array}$ & $\begin{array}{l}\text { Hiperonimia/hipo } \\
\text { nimia. }\end{array}$ \\
\hline
\end{tabular}

Jornadas de Formación e Innovación Docente del Profesorado | № 1 (2018)

(c) Esta obra se distribuye con la licencia Creative Commons Reconocimiento-NoComercialSinObraDerivada 4.0 Internacional (CC BY-NC-ND 4.0.) 


\begin{tabular}{|c|c|c|c|c|c|c|}
\hline $\begin{array}{l}\mathrm{A} \\
\mathrm{P}\end{array}$ & $\begin{array}{l}\text { Fase 1: por grupos, } \\
\text { establecer nuevos } \\
\text { significantes para } \\
\text { los iconos de } \\
\text { ikonikus. } \\
\text { Fase 2: por grupos } \\
\text { pares juegan a unir } \\
\text { significado y } \\
\text { significante. }\end{array}$ & $\begin{array}{l}\text { Fase 1: elegimos un } \\
\text { objeto cercano y le } \\
\text { damos nuevas } \\
\text { características } \\
\text { teniendo en cuenta } \\
\text { el nivel } \\
\text { sociolingüístico y } \\
\text { pragmático. } \\
\text { Fase 2: puesta en } \\
\text { común }\end{array}$ & $\begin{array}{l}\text { Fase 1: De manera } \\
\text { individual creamos } \\
\text { poemas visuales } \\
\text { siguiendo el modelo } \\
\text { de Joan Brossa. } \\
\text { Fase 2: reflexionamos } \\
\text { sobre la relación entre } \\
\text { poesía e imagen }\end{array}$ & $\begin{array}{l}\text { En grupos, } \\
\text { diseñamos } \\
\text { actividades sobre } \\
\text { posibles usos de la } \\
\text { poesía visual de } \\
\text { Chema Madoz en } \\
\text { EP. }\end{array}$ & $\begin{array}{l}\text { Creamos poemas } \\
\text { visuales a la } \\
\text { manera de Chema } \\
\text { Madoz } \\
\text { relacionando } \\
\text { objetos cuyos } \\
\text { significados sean } \\
\text { sinónimos, } \\
\text { antónimos o } \\
\text { polisémicos. }\end{array}$ & $\begin{array}{l}\text { Creamos poemas } \\
\text { visuales haciendo } \\
\text { uso solo de } \\
\text { hiperónimos } \\
\text { hipónimos }\end{array}$ \\
\hline & S7 & S8 & S9 & $\mathrm{S} 10$ & S11 & \\
\hline & $18 / 10$ & $22 / 10$ & $23 / 10$ & $25 / 10$ & $26 / 10(12 / 11)$ & \\
\hline DI & Esto me identifica & Autorretrato & Black stories & $\begin{array}{l}\text { Sinónimos } \\
\text { antónimos }\end{array}$ & $\begin{array}{l}\text { Lluvia de ideas: } \\
\text { Lo que un } \\
\text { maestro tiene en } \\
\text { la sabe }\end{array}$ & \\
\hline PP & 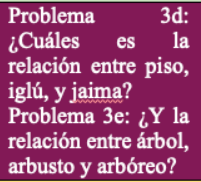 & $\begin{array}{l}\text { Problema 4: ¿Cómo } \\
\text { podemos relacionar } \\
\text { palabra e imagen en } \\
\text { EP? }\end{array}$ & $\begin{array}{l}\text { Problema 5a: ¿Cómo } \\
\text { puedo cambiar el } \\
\text { mundo siendo } \\
\text { maestro de EP? }\end{array}$ & $\begin{array}{lr}\text { Problema } \quad 5 \text { b: } \\
\text { ¿Cómo puedo } \\
\text { cambiar mi entorno } \\
\text { inmediato siendo } \\
\text { maestro de EP? }\end{array}$ & $\begin{array}{l}\text { Problema 6: } \iota \text { Qué } \\
\text { cualidades tiene } \\
\text { que tener un } \\
\text { maestro de EP? }\end{array}$ & \\
\hline $\begin{array}{l}\mathrm{A} \\
\mathrm{y} \\
\mathrm{A}\end{array}$ & $\begin{array}{l}\text { El campo semántico } \\
\text { y la familia léxica }\end{array}$ & $\begin{array}{l}\text { Exposición de todos } \\
\text { los poemas visuales } \\
\text { realizados }\end{array}$ & La metodología ApS & $\begin{array}{l}\text { Puesta en común de } \\
\text { los talleres. } \\
\text { Posibles mejoras. }\end{array}$ & $\begin{array}{l}\text { Realización de un } \\
\text { mapa visual con } \\
\text { las conclusiones }\end{array}$ & \\
\hline $\begin{array}{l}\mathrm{G} \\
\mathrm{R}\end{array}$ & $\begin{array}{l}\text { Creamos poemas } \\
\text { visuales que } \\
\text { describan la familia } \\
\text { léxica y el campo } \\
\text { semántico } \\
\end{array}$ & $\begin{array}{l}\text { Puntuación de los } \\
\text { poemas visuales. } \\
\text { Entrega de premios. }\end{array}$ & $\begin{array}{l}\text { Creación de un taller } \\
\text { de poesía visual en EP }\end{array}$ & $\begin{array}{l}\text { Aplicación de las } \\
\text { mejoras }\end{array}$ & $\begin{array}{l}\text { Preguntas } \\
\text { finales escalera } \\
\text { de aprendizaje }\end{array}$ & \\
\hline
\end{tabular}

\section{Aplicación del ciclo de mejora}

Se presenta a continuación el diario del desarrollo de las sesiones en las que se aplicó el ciclo de mejora en el que se pueden detectar algunos cambios como la unificación de sesiones por plantearse inicialmente un contenido demasiado breve:

Sesión 1: 01/10/2018

Comenzamos la primera sesión jugando al Ikonikus, un juego de mesa para aprender a desarrollar la comprensión del lenguaje visual, la gestión de las emociones y la expresión y la comprensión orales. Se reparten las cartas del juego por las mesas para que trabajen por pequeños grupos. Se explica además la dinámica que van a seguir las clases para este tema de Semántica. La actividad tuvo mucho éxito.

En un segundo momento se les explica la finalidad de las escaleras de aprendizaje y se ponen las preguntas en la pizarra digital.

Jornadas de Formación e Innovación Docente del Profesorado | № 1 (2018)

(c) Esta obra se distribuye con la licencia Creative Commons Reconocimiento-NoComercialSinObraDerivada 4.0 Internacional (CC BY-NC-ND 4.0.) 
A continuación, pasamos a poner en común la respuesta obtenida de la primera pregunta: ¿Cómo nombramos las cosas? Surgen ideas, pero todos parecen esperar una respuesta inmediata. En la pizarra se van apuntando las ideas más significativas. Se les presenta además un dilema para construir entre todos el aprendizaje: dos imágenes de dos martillos, con el fin de encontrar los elementos comunes y la razón de que dos imágenes diferentes compartan el mismo término para nombrarlos. Se pasa entonces a la aclaración de los términos presentados: sema y semema, tomando como ejemplo las ideas que han ido presentando con la actividad de las ideas previas. Una vez aclarado y con una participación muy activa por parte del alumnado se pasa a aclarar el segundo concepto: significado y significante. De nuevo, los alumnos presentan sus dudas, que se van resolviendo en gran grupo conforme van apareciendo.

Para afianzar los contenidos, se invita a los alumnos a retomar las cartas y aplicar lo aprendido por grupos, definiendo significante, ya que el significado sería la propia carta, y destacando sema y semema. Se va por los grupos resolviendo dudas puntuales y comprobando que se han adquirido los conocimientos presentados. La clase acaba con una puesta en común y una respuesta a la pregunta propuesta, recordando los contenidos vistos.

Sesión 2: 4/10/2018

Esta sesión ha comenzado con una dinámica de inicio centrada en el juego Dixit, que consiste en un juego de cartas con imágenes oníricas que cada uno debe relacionar con una palabra dada.

A continuación, se ha planteado la pregunta que ha dirigido la sesión: ¿Qué influye en el nombre de las cosas? Por grupos pequeños han debatido las distintas opciones y hemos hecho una puesta en común en la pizarra. Además, se les han mostrado una serie de imágenes para debatir en gran grupo y terminar de completar esas ideas previas que han ido apareciendo.

Jornadas de Formación e Innovación Docente del Profesorado I № 1 (2018)
Esta obra se distribuye con la licencia Creative Commons Reconocimiento-NoComercialSinObraDerivada 4.0 Internacional (CC BY-NC-ND 4.0.) 
Una vez conocidas las ideas previas, se han ordenado con una explicación teórica sobre las tres disciplinas que estudian la influencia sobre el significado de las palabras: sociolingüística, pragmática y lexicología, relacionando los contenidos previos presentados con las explicaciones teóricas. Por último, se ha explicado la lexicografía.

Para finalizar la sesión, hemos llevado a cabo una pequeña práctica en la que los alumnos debían debatir con sus cartas de Dixit qué elementos sociolingüísticos y cuáles pragmáticos influían en su manera de nombrar las cosas, haciendo así uso también de la lexicología y comprobando la adquisición de los conceptos. Este tiempo de trabajo en grupos ha servido además para ir resolviendo dudas puntuales sobre los contenidos nuevos.

Frente a la sesión anterior, se ha solucionado el problema de la temporalización, ya que en esta se ha incluido algo más de materia (incluida en la última versión del programa de la asignatura, aprobado hace solo unos días), por lo que completaría lo ya presentado. Como en la sesión anterior, la participación de los alumnos ha sido muy buena, estando muy motivados y menos desconcertados que en la primera sesión, ya que van cogiendo el ritmo de la metodología aplicada.

\section{Sesión 3: 8/10/2018}

La sesión se inició con una dinámica que buscaba favorecer el fomento de la creatividad en el alumnado. En este caso, pusimos una canción de Ara Malikian y les dimos a los alumnos libertad para ir dibujando sobre un papel lo que fuera surgiendo: sentimientos, emociones, palabras clave, etc.

A continuación, planteamos la pregunta clave: ¿Cuál es la relación entre palabra e imagen? Tras un breve debate en grupos reducidos, proyectamos una serie de imágenes que se corresponden con los poemas visuales de Joan Brossa, realizados con objetos y dibujos. Se invitó a los alumnos a establecer, de manera individual, la relación entre los títulos de las obras y la imagen que se mostraba. 
Una vez pasadas todas las imágenes, por grupos de trabajo, pusieron en común los nombres y las relaciones. En este tiempo, la docente se paseó por las mesas, supervisando la realización del trabajo. Por último, se hizo una puesta en común en grupo grande parándose en cada una de las imágenes. A continuación, como explicación teórica, se dieron algunas pinceladas sobre la metodología del Visual Thinking o Pensamiento Visual.

Como aplicación práctica, se pidió a los alumnos que creasen su propio poema visual, poniéndolo de nuevo en común con los compañeros y reflexionando sobre las relaciones entre palabra e imagen y su aplicación en EP.

Sesión 4: 9/10/2018

Esta sesión fue grabada por un miembro del equipo de la REFID como sesión modelo inicial. Se les explicó a los alumnos la finalidad.

Comenzamos la sesión con una dinámica para trabajar la creatividad en el aula, en este caso haciendo garabatos y dándoles forma. Se hicieron dos rondas: una creando pajaritos y una segunda completamente libre.

Al igual que en la sesión anterior, se planteó la pregunta clave, relacionada con la anterior, pero con el matiz de que en esta sesión se ha trabajado con fotografía: ¿Qué relación hay entre poesía y fotografía? Por necesidades temporales y en vista de que había que recortar la sesión por una reunión de prácticas, se entró directamente en la proyección de imágenes de Chema Madoz, en las que juega con el lenguaje y la imagen. Al igual que el día anterior, se invitó a los alumnos a observar las imágenes e interactuar con ellas, pero, en este caso, dándoles un título, ya que es característica de la obra de Chema Madoz la falta de título. Igual que en la sesión anterior, se les dio un tiempo para ponerlo en común en grupo reducido, con la supervisión de la docente que fue resolviendo dudas, y se puso en común en grupo grande, pasando cada una de las imágenes.

Jornadas de Formación e Innovación Docente del Profesorado I № 1 (2018) Esta obra se distribuye con la licencia Creative Commons Reconocimiento-NoComercialSinObraDerivada 4.0 Internacional (CC BY-NC-ND 4.0.) 
Como aspecto teórico, se presentó de manera muy breve, el concepto de poesía visual, con la proyección de cuatro definiciones dadas por poetas visuales. Como aplicación práctica, se invitó a los alumnos a diseñar dos actividades destinadas a EP y en las que aplicasen los principios de la Poesía Visual.

Por último, cada grupo expuso brevemente en grupo grande una de sus propuestas. Por falta de tiempo, se pidió tan solo una breve descripción de la propuesta, no entrando en profundidad.

\section{Sesión 5: 11/10/2018}

Comenzamos la sesión con una dinámica de creatividad y pérdida de miedo a hablar en público. Para ello, trajimos a clase un rollo de papel higiénico al que llamamos el objeto hablador. Colocados en círculo, los alumnos realizaron dos rondas de participación: una en la que debían hablarle al objeto y otra en la que el objeto les hablaba a ellos.

A continuación, ya sentados en las mesas, iniciamos la clase con una actividad de acertijos sonoros, proponiendo dos canciones cuyos títulos nos iban a dar la clave de los conceptos que íbamos a trabajar: las palabras monosémicas (Teléfono de Aitana y Umbrella (paraguas) de Rihanna) y las polisémicas (Hijo de la Luna de Mecano y el canto de un gallo). Seguidamente aclaramos y dimos definiciones concretas de los términos trabajados.

En una segunda parte de la clase, proyectamos dos preguntas: ¿Cuál es la relación entre rojo, colorado, bermejo y carmesí? ¿Y entre subir y bajar? Sobre la respuesta, sinónimos y antónimos, matizamos de nuevo una definición.

La tercera parte de la clase fue la puesta en práctica de los conocimientos adquiridos, invitando a los alumnos a plasmar en fotografías la representación de dos o más palabras monosémicas, polisémicas, sinónimos y antónimos, teniendo que realizar un mínimo de cuatro fotografías. 
La sesión de hoy la hemos dedicado a ahondar en una de las preguntas iniciales propuestas: ¿Qué puedo hacer yo como futuro maestro de EP para cambiar el mundo? Sobre las respuestas dadas por los alumnos, se ha creado un diagrama que hemos proyectado y que nos ha servido para ahondar en sus respuestas. Para facilitar la reflexión, primero individual, luego en grupo de trabajo y luego en gran grupo, hemos planteado cuatro preguntas clave: ¿Qué valores transmito? ¿Cómo transmito esos valores? ¿En qué influye la innovación educativa? ¿Cómo fomento el pensamiento crítico? El tiempo dedicado a esta actividad ha sido mucho más largo del que originalmente estaba planeado, pero al ver la implicación de los alumnos, se ha priorizado la reflexión por encima del cumplimiento de la temporalización.

Tras ponerlo en común con el gran grupo y haciendo una reflexión general en la que hemos recogido en general las ideas, hemos realizado otra dinámica titulada etiquetas. Con una imagen de las Tres mil viviendas proyectada, les hemos repartido un post-it a cada alumno y los hemos invitado a escribir la primera palabra que se les viene a la cabeza cuando piensan en esa barriada. Una vez que todos han acabado, hemos dividido una parte de la pizarra en tres: positivo, neutro y negativo y los hemos invitado a situar sus ideas en cada uno de los apartados. El resultado ha sido una gran aglomeración en lo negativos, con algunas notas neutras y otras positivas. El efecto visual ha sido muy potente y hemos leído algunas, la mayoría referentes al miedo o a la pobreza.

La tercera parte de la clase se ha centrado en la explicación de la metodología del Aprendizaje Servicio como modo de cambiar el mundo desde la educación y como posibilidad de aplicación voluntaria del taller de poesía visual que tienen que elaborar como resultado de este bloque de contenido. Se les ha invitado además a hacerlo con Fundación Alalá, explicando en qué consiste su labor

Jornadas de Formación e Innovación Docente del Profesorado I № 1 (2018)
Esta obra se distribuye con la licencia Creative Commons Reconocimiento-NoComercialSinObraDerivada 4.0 Internacional (CC BY-NC-ND 4.0.) 
y proyectando el tráiler del documental. Por último, se han expuesto las características que tiene que tener el taller, horarios disponibles, etc. además de la secuencia de trabajo, tanto si se opta por la opción de llevarlo a cabo de manera voluntaria, como si no.

Como evaluación final, y para recoger todas las emociones que se han removido, hemos invitado a los alumnos a escribir en la pizarra la emoción que tenían en ese momento.

Sesión 7: 18/10/2018

Hoy hemos comenzado la clase situándonos dentro de la asignatura y del tema, comprobando en grupo grande el progreso de los estudiantes. A continuación, hemos comenzado con la dinámica de inicio basada en el juego de cartas Black Stories, con la que hemos trabajado la creatividad y el pensamiento visual.

Luego hemos proyectado unas imágenes relacionadas entre sí: margarita, rosa y clavel y pan, empanadillas, empanada y panadería. En el primer caso, se trata del campo semántico, en el segundo de la familia léxica. Tras una puesta en común para las ideas previas, hemos matizado los conceptos teóricos.

Como parte práctica, hemos hecho uso de la aplicación WallaMe que los alumnos debían haberse descargado la semana anterior y que consiste en una aplicación de realidad aumentada. En este caso, le hemos propuesto a los alumnos que creasen imágenes que recogiesen el campo semántico de palabras elegidas por ellos, compartiéndolas con los compañeros y realizando una especie de caza del tesoro, siguiente la dinámica del popular juego PokemonGo. Ya de vuelta en clase, hemos hecho una breve puesta en común sobre la aplicabilidad de la actividad en una clase de EP.

Sesión 8: 22/10/2018

Esta sesión ha comenzado con una dinámica titulada autorretrato con la que hemos tratado de concienciar a los alumnos sobre el acoso escolar. Para conseguirlo, les

Jornadas de Formación e Innovación Docente del Profesorado I № 1 (2018)
Esta obra se distribuye con la licencia Creative Commons Reconocimiento-NoComercialSinObraDerivada 4.0 Internacional (CC BY-NC-ND 4.0.) 
hemos invitado a dibujar en un papel su autorretrato, pudiendo añadir todos los detalles que creyeran necesarios para reconocerse. Conforme han ido terminando, hemos ido recogiendo, mezclando y cruzando los dibujos con los de los compañeros, de manera que todos han recibido el retrato de una persona diferente. A continuación, se les ha indicado que debían hacer una bola de papel lo más pequeña posible para lo que podrían estrujar, apretar, etc. el papel que habían recibido. Una vez superada esta tarea, se les ha invitado a tratar de devolver el papel a su forma original: liso, sin arrugas... Todos han comenzado a aplastarlo con las manos, marcarlo con una regla, incluso usar el canto de la mesa para intentar dejarlo lo mejor posible, lo que es, claramente imposible. La lección que se ha compartido es que por mucho que intentemos devolver a una persona que ha sufrido acoso a su forma original, ya siempre le quedará algún pliegue, alguna arruga.

La parte central de la sesión la hemos dedicado a que los alumnos trabajaran el taller de poesía visual por grupos, resolviendo dudas que han ido surgiendo.

Por último, hemos hecho una dinámica titulada: ¿Qué tiene un maestro de EP en la cabeza? Sobre un cerebro en blanco proyectado en la pantalla, los alumnos han tenido que poner en un post-it las capacidades, aptitudes, etc. que traen ya adquiridas (a la izquierda) y en otro las que han adquirido o creen que pueden adquirir en la titulación (derecha). El resultado ha sido una imagen muy visual de la cantidad de cosas que ya traen de casa, lo que ha servido para motivarles a adquirir las que creen necesarias y hacer una reflexión conjunta sobre las más importantes.

Sesión 9: 23/10/2018

Esta ha sido la última sesión teórica del tema. En ella nos hemos centrado en los diccionarios: sus tipos, estructura y su utilidad. Para comenzar la sesión, y teniendo en cuenta la buena acogida que han tenido este tipo de dinámicas (así lo han hecho constar en los diarios de clase), hemos ido proyectando una serie de palabras y su origen

Jornadas de Formación e Innovación Docente del Profesorado | № 1 (2018)

Esta obra se distribuye con la licencia Creative 
etimológico, haciendo uso de la aplicación enclave de la RAE. Palabras como subasta, coco, libélula o tortuga.

A continuación, hemos preguntado sobre las ideas previas de los contenidos teóricos a impartir: ¿Qué es un diccionario? ¿Para qué sirve? ¿Cuántos tipos de diccionarios hay? Para, a partir de la puesta en común en grupo grande, aclarar los conceptos teóricos y matizar las definiciones dadas por los propios alumnos.

Para poner en práctica lo aprendido y ver la utilidad y aplicabilidad de los diccionarios, les hemos dado a los alumnos una serie de palabras que hacen referencia a elementos que usamos diariamente, pero cuyo nombre desconocemos: escrupulillo, agrafe, jeme, luquete, giste o telsón. Por grupos, han tenido que buscar en el diccionario las diferentes acepciones para luego poner en común el significado. Ha sido una actividad que les ha gustado mucho, ya que han descubierto palabras que no conocían y este es un grupo que destaca por su curiosidad, por lo que en todo momento se intenta aprovechar esa característica. Por último, para cerrar la sesión, se les han dado algunas posibles aplicaciones del uso de diccionarios en EP.

\section{Sesión 10 y Sesión 11: 25/10/2018 y 12/11/2018}

La última sesión se ha dedicado en exclusiva al trabajo del taller de poesía visual y a la resolución de dudas sobre el tema que se han ido recogiendo de los diarios de aprendizaje. La sesión 11 sirvió de introducción para el siguiente tema y para que los alumnos completaran las cuestiones finales. Ha sido con tanto retraso por enfermedad de la profesora.

\section{Evaluación del aprendizaje. Escaleras de aprendizaje}

A continuación, podemos observar la evolución en el aprendizaje de los alumnos: azul para las evaluaciones iniciales y naranja para las finales. En las iniciales participó un total de 59 alumnos frente a los 55 de las finales. 


\section{1. ¿Cómo nombramos las cosas?}

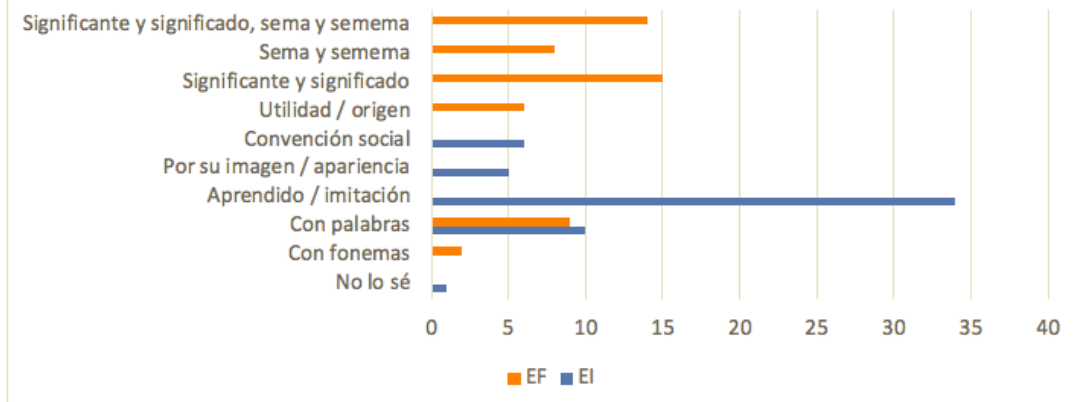

Figura 5. Escalera 1. ¿Cómo nombramos las cosas?

\section{2. ¿Qué influye en el nombre de las cosas?}

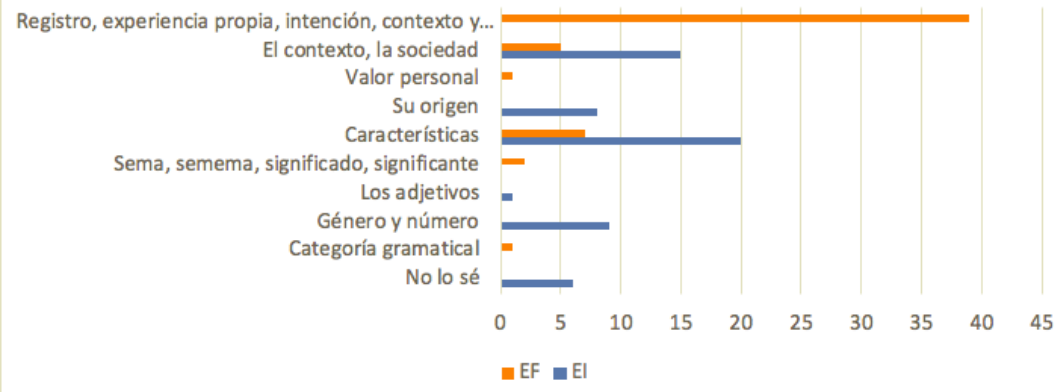

Figura 6. Escalera 2. ¿Qué influye en el nombre de las cosas?

3. ¿Cómo puedo relacionar palabra e imagen en el área de Lengua Española en EP?

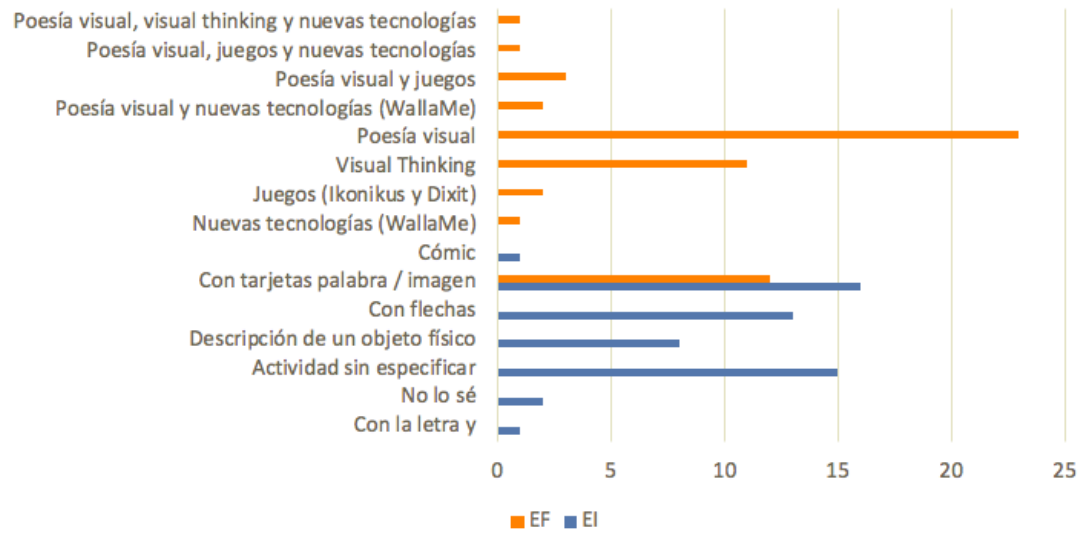

FiguraFigura 7. Escalera 3. ¿Cómo puedo relacionar palabra e imagen en el área de Lengua Española en EP?

Jornadas de Formación e Innovación Docente del Profesorado | № 1 (2018)

(c) (i) $\odot$ Esta obra se distribuye con la licencia Creative Commons Reconocimiento-NoComercialSinObraDerivada 4.0 Internacional (CC BY-NC-ND 4.0.) 


\section{4. ¿Qué cualidades debe tener un maestro de EP?}

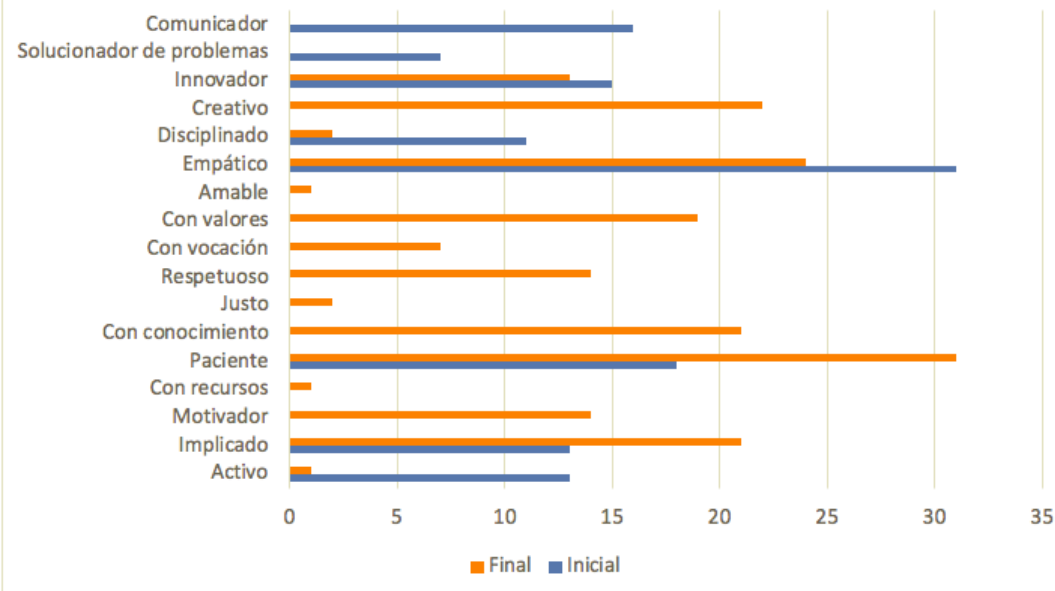

Figura 8. Escalera 4. ¿Qué cualidades debe tener un maestro de EP?

5. ¿Cómo puedo cambiar el mundo siendo maestro de EP?

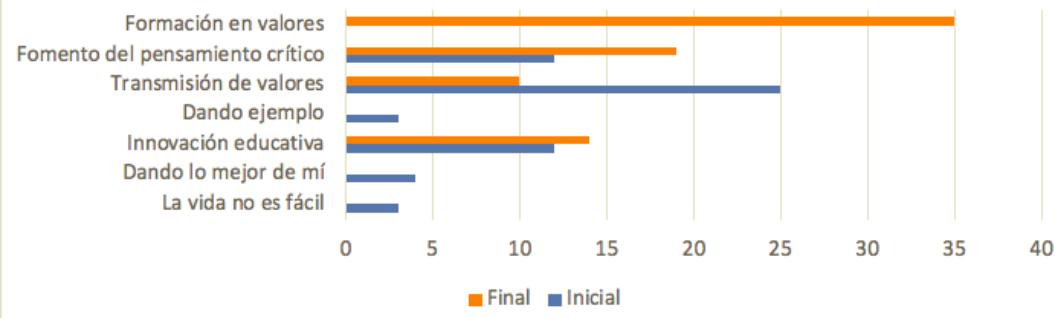

Figura 9. Escalera 5. ¿Cómo puedo cambiar el mundo siendo maestro de EP?

Sobre los resultados obtenidos en las tres primeras preguntas clave destaca la evolución del alumnado en sus respuestas por la especialización que se ha producido, pasando de responder con ideas más vagas a conceptos que se encuentran entre los contenidos del tema: significante y significado, sema y semema, en el caso de la primera; el incremento en el conocimiento de factores que influyen en el nombre de las cosas y un uso más acertado de las palabras clave, en la segunda, o un aumento en su conocimiento de nuevas metodologías como el uso del visual thinking o su conocimiento de la poesía visual, en tercera.

Jornadas de Formación e Innovación Docente del Profesorado | № 1 (2018)

(7) Esta obra se distribuye con la licencia Creative Commons Reconocimiento-NoComercial- 
Respecto a las preguntas cuatro y cinco, el objetivo era detectar las ideas de los alumnos antes y después de presentar en clase contenidos actitudinales. En el caso de la pregunta 4, destaca la inclusión de muchos más valores en las evaluaciones finales que en las finales, llamando además la atención que valores como la creatividad o los valores personales, sin ningún resultado en las encuestas iniciales, aparezcan en las finales como un valor muy alto. Por otra parte, el resultado más revelador de la pregunta 5 es la evolución que han sufrido las respuestas, seguramente sin una conciencia plena por parte del alumnado, que han pasado de "transmisión de valores" a "formación en valores", presentándose este cambio como la realización de dinámicas con el alumnado, no con un mero nombramiento de los valores esenciales.

\section{Evaluación del ciclo de mejora}

Para evaluar el aprendizaje no hemos hecho solo uso de las escaleras de aprendizaje, sino también de otros instrumentos. En primer lugar, el portafolio, donde se ha recogido el taller de poesía visual, en el que los alumnos han tenido que aplicar los contenidos conceptuales (nociones de semántica), procedimentales (diseño de una actividad) y actitudinales (visibilización de un colectivo marginal). Además, para la autoevaluación docente, hemos hecho uso tanto la observación directa como del diario de aprendizaje semanal. Este instrumento nos ha servido para ir adaptando el ritmo y comprobando de manera informal la adquisición y comprensión de los conceptos presentados. Además, en la sesión 6 incluimos una lluvia de ideas en la que evaluamos la situación emocional del alumnado frente al bloque y el desarrollo de la asignatura.

En base a estos instrumentos y momentos de evaluación, podemos concluir que el ciclo de mejora ha cumplido con los objetivos inicialmente presentados, consiguiendo que una asignatura que inicialmente se presentaba como 
muy tediosa para los alumnos haya terminado siendo una de las más esperadas de la semana. Como aspecto a mejorar, resaltaríamos la necesidad de trabajar más en profundidad la temporalización de los contenidos, aspecto que hemos detectado al aplicar el ciclo de mejora en el que se pueden apreciar cambios entre la versión inicial y la final, ya que el tema quedaba corto para la duración planificada.

\section{Referencias bibliográficas}

Bain, K. (2007). Lo que hacen los mejores profesores universitarios. Valencia: Publicaciones de la Universidad de Valencia.

Finkel, D. (2000). Dar clase con la boca cerrada. Valencia: Públicaciones de la Universidad de Valencia.

Jornadas de Formación e Innovación Docente del Profesorado | № 1 (2018)

(c) Esta obra se distribuye con la licencia Creative Commons Reconocimiento-NoComercial- 